\title{
GENERALIZATIONS OF HÖLDER'S INEQUALITIES ON TIME SCALES
}

\section{DENIZ UÇAR AND ALi DENIZ}

Abstract. Hölder's inequalities and their extensions have received considerable attention in the theory of differential and difference equations. In this paper, we establish some new generalizations and refinements of Hölder's inequality and some related inequalities on time scales. We also show that many existing inequalities related to the Hölder's inequality are special cases of the inequalities presented on time scales.

Mathematics subject classification (2010): 26B25, 26D15, $26 \mathrm{E} 70$.

Keywords and phrases: Hölder's inequalities, time scales, integral inequalities.

\section{REFERENCES}

[1] S. Abramovich, B. Mond and J. E. PeČarić, Sharpening Hölder's inequalities, J. Math. Anal. Applications 196, 3 (1995), 1131-1134.

[2] R. Agarwall, M. Bohner And A. Peterson, Inequalities on time scales: A survey, Math. Inequalities and Applications 4, 4 (2001), 535-557.

[3] E. F. Beckenbach, R. Bellman, Inequalities, Springer-Verlag, Berlin, 1961.

[4] M. Bohner, A. Peterson, Dynamic Equations on Time Scales, An Introduction with Applications, Birkhauser, Boston, 2001.

[5] D. K. Callebaut, Generalization of the Cauchy-Schwarz inequality, J. Math. Anal. Applications 12, 3 (1965), 491-494.

[6] E. Hewitt, K. Stromberg, Real and Abstract Analysis, Springer-Verlag, Berlin, 1975.

[7] M. MASJED-JAMEI, A functional generalization of the Cauchy-Schwarz inequality and some subclasses, Appl. Math. Letters 22, 9 (2009), 1335-1339.

[8] D. S. Mitrinović, P. M. Vasić, Analytic Inequalities, Springer-Verlag, New York, 1970.

[9] H. QIAng, Z. Hu, Generalizations of Hölder's and some related inequalities, Comp. and Math. with Applications 61, 2 (2011), 392-396.

[10] C. WInG-Sum, Generalizations of Hölder's inequality, Int. J. of Mathematics and Mathematical Sciences 26, 1 (2001), 7-10.

[11] S. Wu, L. Debnanth, Generalizations of Aczel's inequality and Popoviciu's inequality, Indian J. Pure Appl. Math. 36, 2 (2005), 49-62.

[12] S. WU, A new sharpened and generalized version of Hölder's inequality and its applications, Appl. Math. Comput. 197, 2 (2008), 708-714.

[13] X. YAng, A generalization of Hölder inequality, J. Math. Anal. Appl. 247, 1 (2000), 328-330. 